from ATP to immunoglobulin or to middle $T$ itself in immunoprecipitates of polyoma tumour antigens; it is thus impossible directly to implicate a virus-coded protein in the enzymatic reaction. However, kinase activity is detected in plasma membrane fractions, the location of middle $T$, and in transformed cell lines which lack large $T$ but contain middle T. Moreover, there is no kinase activity in the cell line that contains the integrated DNA of an $h r-t$ mutant and thus produces large $T$ but not middle $T$. These results raise the possibility that middle $T$ is a kinase, but they cannot rule out that the enzyme activity is a property of one of the other, less well characterised, viral proteins found in immunoprecipitates, or of a cellular protein that binds specifically to middle $T$.

In the immediate future we can expect the application of recombinant DNA techniques to lead to a detailed description of the integrated viral DNA found in transformed cells and of the mRNA species synthesised from it. In the longer term the central question to be addressed regarding the molecular biology of SV40 and polyoma will concern the enzymatic activities of the tumour antigens and the cellular targets on which these proteins act.

\section{Ancient plate speeds}

from Peter J. Smith

Absolute speeds of the Earth's lithospheric plates are generally lower for those plates having the greater proportions of continents, higher for those plates having the lengthier subducting edges, and higher for those plates with the greater colatitudes. But can these generalisations be regarded as universal rules holding over all time, or are they merely conclusions temporarily valid under current circumstances? Certainly the statistics are hardly impressive enough to inspire confidence in universality. It is true, for example, that all the plates having large continental components $\left(>2 \times 10^{7} \mathrm{~km}^{2}\right)$ have low speeds ( $<30 \mathrm{~mm}$ a year); but there are only four of them, or not really enough to support the conclusion that large continents always move slowly. More generally, it would be rash to impute timelessness to any conclusion drawn from the behaviour of the mere 10-12 major plates in existence today.

On the other hand, investigation of past plate speeds is difficult. One approach would be to calculate absolute plate motions on the assumption that the Earth's hot spots are fixed with respect to the mantle; but it is not entirely clear that the assumption is valid, and ancient hot spot

Peter J. Smith is Reader is the Department of Earth Sciences, The Open University. traces are difficult to recognise anyway. Solomon et al. (J. geophys. Res. 82, 203; 1977) made rather more progress when they estimated plate motions during the early Tertiary on the assumption that there was no net torque between the lithosphere and mesosphere, concluding that generalisations derived from current plate behaviour were not always true in the past. But there is a limit on how far back in time this method can be applied, for it requires complete knowledge of ancient plate boundaries. It is also rather sensitive to the (usually unknown) amount of intraplate deformation which has occurred since.

In view of such difficulties, Gordon et al. (J. geophys. Res. 84, 5480; 1979) have now devised a third method of estimating ancient plate motions - one based on palaeomagnetic data. The advantages of such a technique are that palaeomagnetic results for many continents cover at least several hundred million years and that it is possible in principle to determine apparent polar wandering paths with considerable accuracy. The most serious disadvantage, however, is that palaeomagnetism does not give the information necessary to specify continental motion in full. What Gordon and his colleagues have done is to devise a method whereby the data inherent in the polar wandering curve are converted into the rms velocity of the plate - a by no means simple procedure, for the precise relationship of apparent polar wandering to continental drift depends on the position of the continent with respect to the plate's pole of rotation. Because of the fundamental incompleteness of palaeomagnetic data, however, what emerges is not the actual rms velocity of a plate but a minimum rms velocity.

Obviously this is not ideal, but it turns out to be far from useless. Gordon et al. have applied their technique to the polar wandering curves for North America, Eurasia and Gondwanaland as specified by Irving (Nature 270, 304; 1977) for the past 350 million years. The results clearly show that the relevant minimum rms continental velocities $\left(V_{\mathrm{m}}\right)$ have certainly not remained constant over that period. For North America $V_{\mathrm{m}}$ peaked about 190 million years ago at a value of more than twice the present one, and similar maxima occurred for Gondwanaland a few tens of millions of years earlier and for Eurasia slightly later. Indeed, the peak values of $V_{\mathrm{m}}$ were almost as great as the actual $\mathrm{rms}$ velocities of present oceanic plates. In each case the period of particularly rapid motion probably lasted 20-30 million years, which is more than sufficient to indicate that plates with large continents can move rapidly when circumstances permit.

In other words, both largely oceanic and largely continental plates are capable of moving rapidly (that is, at velocities greater than $60 \mathrm{~mm}$ a year) - which must mean that the resistance to motion of continental lithosphere cannot be substantially greater than that of oceanic lithosphere. The implication is that the present low velocities of continental plates arise from an accident of plate geometry. Gordon and his coworkers go on to speculate that the chief factor governing plate velocity is the proportion of plate boundary attached to subducting slabs. It just so happens that at present the largely continental plates are short on subduction zones; ergo, they are now moving only slowly.

Nevertheless, it may be quite wrong to conclude from all this that at any given time continental plates are just as likely to be travelling as fast as oceanic plates. Continental plates evidently can move as fast as oceanic plates, but the latter probably spend a higher proportion of their time actually moving rapidly than do the former. For although the motional resistances of the two types of plate may be comparable, the subduction cycles of the two may be quite different. Put very briefly, because continental and oceanic lithospheres behave rather differently when approaching and meeting trenches, subduction of an oceanic plate will continue for much longer than subduction of an otherwise comparable continental plate. The result, according to Gordon $e t$ $a l$. , is that "Statistically . . . plate motions sampled at a given instant of time, such as the present, are likely to show a negative correlation between plate velocity and continental area."

\section{0 years ago}

There is much more than the name of Cambridge to remind one of its namesake at home. Its quiet air of studious retirement, its quaint buildings and tree-shaded walks have much of the mother-country about them. One or two features of the place, however, are characteristically American. Thus in the great library at Gore Hall, most of the work of receiving and distributing books is done by young women, and done, too, with a noiseless decorum and celerity worthy of all praise. A magnificent Memorial Hall to those graduates of Harvard who fell in the late Civil War bears witness in its crowded lists of names that culture and courage may go hand in hand.

While Harvard is necessarily the great centre of scientific research, much admirable work is done in Boston in the way of practically expounding science. The Institute of Technology has for its primary object the education of the community in these branches of scientific knowledge conducive to progress in the arts and industries of life. In pursuance of this aim the methods of tuition are so practical and thorough that the results must be felt far beyond the industrial circles. Established mainly through the enlightened zeal of the present venerable President of the National Academy, Prof. W. B. Rogers, it began a few years ago to languish, but its founder has recently come back to its rescue, throwing himself into its affairs with all his old heartiness and kindliness until, freshened and stimulated by his influence, it is once more shooting up into lusty vigour.

From Nature 21, 18 Dec., 150; 1879. 